\title{
DESTRINCHANDO A CONSTRUÇÃO METAFÓRICA DE UM ESPAÇO DE CRENÇAS SOBRE APRENDER A PRONÚNCIA DE UMA LÍNGUA ESTRANGEIRA
}

Unraveling the metaphoric construction of a belief space about learning the pronunciation of a foreign language

\section{Ana Maria dos Santos Garcia Ferreira MARTINS - UTFPR ${ }^{1}$}

\begin{abstract}
RESUMO: Recentemente, estudos sobre crenças em contexto de ensino e aprendizagem de língua estrangeira têm sido realizados a partir de abordagem metodológica contextual e discursiva. Com essa abordagem, instrumentos de pesquisa diferentes dos questionários com escala likert passaram a ser considerados; entre eles, o uso de metáfora tem sido explorado para conhecimento dos dados. Seguindo essa abordagem mais recente, o objetivo desta pesquisa de cunho interpretativista qualitativa é destrinchar metáforas que representam crenças de alunos sobre a aprendizagem da pronúncia da língua estrangeira. Para isso, 40 alunos do Curso de Letras Inglês da UTFPR foram abordados e dez deles completaram uma frase dada criando assim metáforas. Oito dessas metáforas foram categorizadas em grupos conceituais metafóricos; posteriormente, cada uma delas foi explorada conforme seus aspectos paradoxais; e então, elas foram destrinchadas através de questionamentos sobre seus diferentes elementos. $\mathrm{O}$ resultado desse destrinchamento mostra algumas possibilidades de leitura das crenças dos alunos sobre a aprendizagem da pronúncia da língua estrangeira. Essas possibilidades, porém, foram colocadas como sugestões que podem contribuir para o entendimento da forma de pensar dos participantes, bem como para a dinâmica de sala de aula. Elas não se apresentam como uma reflexão esgotada, ao invés disso, se mostram como um recurso que pode e deve ser modificado conforme a trajetória dos envolvidos.
\end{abstract}

PALAVRAS-CHAVE: crenças; língua estrangeira; aprendizagem da pronúncia; metáforas; destrinchamento

ABSTRACT: Recently, studies on beliefs in the context of teaching and learning a foreign language have been run from a contextual and discursive approach. Along with this approach, research instruments different from Likert scale questionnaires started to be considered; among them, the use of metaphors has been explored in order to get to know the research data. Considering this more recent approach, the aim of this interpretativist qualitative research is to unravel metaphors that represent students' beliefs about learning the pronunciation of a foreign language. In order to do that, 40 undergraduate students of Letras Inglês at UTFPR were approached, and ten filled up a given sentence and built metaphors; then, eight of them were categorized into conceptual metaphoric groups; after that, each one of them was explored according to its paradoxical features; and afterwards, they were unraveled through questioning their different elements. The result of this unraveling shows some possibility of reading the students' beliefs about the learning process of the pronunciation of a foreign language.

\footnotetext{
${ }^{1}$ Universidade Tecnológica Federal do Paraná - Curitiba
} 
REVISTA X, Curitiba, volume 14, n.3,227-250, 2019.

Theses possibilities, however, were considered as suggestions that may contribute to the understanding of the students' way of thinking, and the dynamics in the classroom, as well. They are not presented as a reflection that has been fully explored; instead, they appear as a resource that can and must be modified according to the trajectory of the people involved in the process.

KEYWORDS: beliefs; foreign language; pronunciation learning; metaphor; unravelling

\section{INTRODUÇÃO}

Pesquisas que tratam do estudo de crenças na aprendizagem de Língua Estrangeira (LE) começaram a aparecer no cenário da Linguística Aplicada (LA) no exterior, nos anos 80. Trabalhos como os de Wenden (1986) e de Horwitz (1988) marcam o início dessa trajetória. No Brasil, conforme Barcelos (2003) as pesquisas sobre esse assunto tiveram início em meados dos anos 90. Entre os trabalhos dessa época, temos Almeida Filho (1993), e a pesquisa de mestrado da própria Barcelos (1995). A autora estabelece esse marco nos trabalhos sobre crenças ao verificar que os anais do Congresso da Associação de Linguística Aplicada do Brasil (ALAB) de 1995, não traziam nenhuma referência a estudos que investigavam crenças. Ao fazer o mesmo levantamento em 1997, ela encontrou pelo menos quatro trabalhos que tratavam de crenças sobre aprendizagem de línguas.

A partir de então, o número de trabalhos de pós-graduação que investigam crenças no Brasil tem crescido. Um incentivo para esse crescimento pode ter sido a realização de um simpósio sobre crenças na conferência da Associação Internacional de Linguística Aplicada em 1999, e também a publicação de um volume do periódico System dedicado exclusivamente a crenças sobre aprendizagem de línguas (BARCELOS, 2003). Hoje, uma busca a partir das palavras chaves "crenças" e "língua estrangeira" feita no Catálogo de Teses e Dissertações da Capes ${ }^{2}$ traz resultado com mais de 40 mil pesquisas de mestrado e doutorado realizadas nos últimos cinco anos (entre 2014 e 2018), escritos por mais de 39 mil autores.

Com o crescimento do número de pesquisas que trata de crenças, a abrangência delas também se tornou evidente. Há trabalhos que exploram as crenças e também têm foco (a) no acadêmico de Letras como Carvalho (2000), Silva (2001), Barcelos (1995) e Silva (2005); (b) no professor em serviço como em Miranda (2005) e Coelho (2005); (c) em pais, coordenadores e diretores como Rocha (2006); (d) em diferentes contextos

\footnotetext{
${ }^{2}$ Acesso em 28/04/2018 - http://catalogodeteses.capes.gov.br/catalogo-teses/\#!/
} 
REVISTA X, Curitiba, volume 14, n.3,227-250, 2019.

de ensino e diferentes abordagens metodológicas como Cruz (2018) sobre o dizer e o fazer de professores em formação, Teixeira (2018) sobre a identidade do professor de inglês no Tocantins, Avila (2018) sobre crenças em avaliação no ensino de espanhol na escola pública, e Oliveira (2016) sobre crenças, motivações e identidades de alunos de língua inglesa em uma escola particular.

Com o passar dos anos, também houve diversificação nas metodologias de pesquisa aplicadas à pesquisa de crenças, e vários autores têm contribuído com a difícil tarefa de analisar e agrupar as abordagens e conceitos usados na área. Entre eles, Kalaja (1995) classificou as abordagens em convencional e discursiva; Barcelos (2003) chamou as abordagens de normativa, metacognitiva e contextual; Bernat et al. (2009) ajuntou as abordagens em psicocognitiva, sociocultural e ecológica; e Kalaja et al. (2016) designou as abordagens como sendo tradicional e contextual. Todos esses agrupamentos consideram a trajetória que as pesquisas sobre crenças fizeram desde que começaram a investigar o assunto. Entre as diferenças encontradas nas perspectivas das pesquisas, destacamos o fato de as primeiras investigações se destinarem a conhecer e reconhecer quais eram as crenças dos alunos de LE, e trabalhos mais recentes buscam entender como as crenças se desenvolvem e variam nos contextos.

Ainda no que diz respeito à metodologia de pesquisa sobre crenças, vê-se hoje o uso de conceitos como a visão dialógica bakhtiniana, como em Dufva (2018) e Hosenfeld (2018). As autoras usam o construto da heteroglossia e propõem que as crenças são coconstruídas por muitas vozes.

Outro conceito que também tem sido usado para lidar com os dados sobre crenças é o da metáfora para geração de dados, conforme o trabalho de Kramsch (2018) que trata da metáfora e da construção subjetiva das crenças; Sakui e Gaies (2018) que pesquisam as crenças de metáforas de uma professora japonesa de inglês; Littlemore e Low (2006) que tratam da competência metafórica e da habilidade comunicativa; e de Wan, Low e Li (2011) que analisam metáforas sobre o papel do professor de LE. Essas pesquisas variam seus procedimentos, ora usando o processamento de metáfora ora o processo metafórico de outros textos para análise dos dados, conforme distingue Gibbs (1998, 1999). No Brasil, destaco duas dissertações de mestrado que se apoiam no construto de metáfora conceitual de Lakoff e Johnson (2008): Gomes Junior (2011) e Silva (2013); e a tese de doutorado de Barata (2006).

O trabalho de Gomes Junior (2011) identifica as metáforas de universitários de 
diversos cursos de graduação das disciplinas online Inglês Instrumental I e II da $\mathrm{UFMG}^{3}$; e a pesquisa de Silva (2013) processa metaforicamente narrativas multimodais e as organiza em 4 categoriza: 1) aprendizagem de inglês; 2) inglês; 3) aprendizes de inglês; e 4) professores de inglês. A tese de doutorado de Barata (2006), tratou de crenças de quatro professoras em formação, sobre avaliação. Ela desenvolveu sua pesquisa a partir de metáforas encontradas nas falas das participantes.

A contribuição que a metáfora traz para as pesquisas pode ser explicada a partir do entendimento de linguistas cognitivos como Lakoff e Johnson (2008), que apontam que a metáfora é uma parte intrínseca do nosso aparato conceitual. Além disso, esse conceito não é apenas estilístico, mas também cognitivo e linguístico, e se apresenta como um recurso importante para expressar pensamentos inarticulados.

Com isso em mente, considerando conceitos, metodologias e diferentes construtos teóricos, este trabalho se propõe a problematizar metáforas de acadêmicos do primeiro período do Curso de Letras Inglês da UTFPR Campus Curitiba, sobre a aprendizagem da pronúncia de uma LE. Esse processo acontece a partir do que chamo de destrinchamento ${ }^{4}$ das metáforas, o que me permite olhar para cada uma delas de uma forma a questionar e tentar contextualizar os conceitos que elas trazem. Então, seguem as seções que tratarão de aspectos teóricos importantes para o trabalho, da metodologia e da problematização e destrinchamento das metáforas.

\section{REFLEXÕES SOBRE CRENÇAS}

Conforme mencionado anteriormente, o construto de crenças tem sido investigado e reconhecido de maneiras diferentes daquelas que o apresentavam nos anos 80 (no exterior) e 90 (no Brasil). Levantamentos feitos por Pajares (1992), Gimenez (1994) e Barcelos (2001), apresentam diferentes nomes usados para designar crenças. Entre esses termos, vê-se: miniteorias de aprendizagem de língua de alunos (HOSENFELD, 1978), conhecimento metacognitivo (WENDEN, 1986), cultura de aprendizagem (RILEY, 1997) e cultura de aprender línguas (ALMEIDA FILHO, 1993;

\footnotetext{
${ }^{3}$ Universidade Federal de Minas Gerais

${ }^{4}$ Adoto esse termo para designar um processo de questionamento sobre os elementos contidos nas metáforas apresentadas pelos participantes desta pesquisa. Tal questionamento pretende problematizar a aprendizagem da pronúncia de LE, de modo a conhecer as crenças dos alunos sobre o assunto, e trazer subsídios que podem ser importantes para o contexto de ensino e aprendizagem. Esse processo não se apresenta como esgotado; ao invés disso, sugere que outras perguntas sejam feitas além das apresentadas aqui.
} 
REVISTA X, Curitiba, volume 14, n.3,227-250, 2019.

BARCELOS, 1995).

Dentro do conceito de cultura de aprender línguas, o trabalho de Almeida Filho (1993), um dos primeiros a tratar de crenças no Brasil, as apresenta como sendo forças que podem influenciar o processo de ensino e aprendizagem, e que se referem ao conhecimento intuitivo do aluno, formado por concepções e mitos sobre o processo de aprendizagem de línguas. Na mesma perspectiva, Barcelos (1995 e 1999) também trata de crenças a partir do termo cultura de aprender, e destaca que o contato com as crenças pode revelar divergência entre as expectativas que os alunos têm sobre o ensino, e as que os professores têm sobre o aluno, por exemplo.

A perspectiva que adoto para essa reflexão é a que Kalaja e Barcelos (2018, p. 232-233) apresentam ao final de seu livro Beliefs about SLA - New research approaches, quando fazem um apanhado das características das crenças, usadas por diferentes autores ao longo dos capítulos. Esses mesmos aspectos têm servido de base para várias outras pesquisas sobre crenças, como em Barcelos (2006). De acordo com as autoras, as crenças são caracterizadas por serem:

- dinâmicas e emergentes: a partir do que propõe Dufva (2018), as crenças são dinâmicas em dois sentidos: elas podem mudar durante a vida da pessoa e também podem mudar dentro de uma situação momentânea. As crenças são emergentes porque não podem ser vistas como algo estático na mente de alguém, ao contrário, elas se modificam e evoluem conforme experimentamos o mundo, interagimos com ele, modificamos e somos modificados por ele.

- socialmente construídas, contextualmente situadas: em oposição ao conceito de crenças encontrado em pesquisas realizadas a partir da abordagem normativa e metacognitiva (BARCELOS, 2018), as crenças não são entendidas como uma imagem mental e individual; ao invés disso, elas agregam muitas vozes, incorporando, assim, a perspectiva social conforme são criadas nos contextos de grupos sociais e de relacionamentos. Com isso, as crenças são coconstruídas por outros, além da própria pessoa.

- experienciais: as crenças surgem de interações entre o indivíduo e o ambiente (aluno/aluno, aluno/professor, aluno/disciplina/ e assim por diante). Elas não são certas ou erradas (KRAMSCH, 2018); e também não são exatas (WOODS, 2018). As crenças são construídas e reconstruídas para propósitos específicos, situados e contextualizados.

- mediadas: conforme Alanen (2018), as crenças são recursos de mediação que 
REVISTA X, Curitiba, volume 14, n.3,227-250, 2019.

os alunos ou professores podem usar ou não. Ainda, outras pessoas podem agir como mediadores das crenças. É por isso que algumas pessoas podem não agir de acordo com suas crenças, uma vez que as crenças são entendidas como uma ferramenta que está disponível, e eventualmente pode não ser usada conforme a situação, a tarefa ou as pessoas com quem se está interagindo.

- paradoxais e contraditórias: entre os adjetivos usados para exemplificar esse aspecto, pode-se dizer que as crenças são sociais e também individuais; são únicas, mas também são compartilhadas; são racionais, mas também são emocionais; são diversas, mas também são uniformes. Nesse mesmo sentido, Alanen (2018), Dufva (2018) e Barcelos (2018) destacam que as crenças podem ser uma ferramenta para empoderamento ao mesmo tempo em que podem ser barreiras para a aprendizagem de LE.

Reforçando os pressupostos acima, que tratam de crenças a partir de uma perspectiva contextual e discursiva, outro aspecto que também considero importante para a definição de crenças é o usado por Kalaja (2018) e Kramsch (2018), que deixam de entender crenças como entidades cognitivas, que é um conceito com base na teoria da atribuição do final dos anos 40 e início dos anos 50 (HEIDER, 1944, 1958), e que é influenciado pela psicologia cognitiva. Esses construtos teóricos, consequentemente, têm raiz nas abordagens positivistas de pesquisa, e atuam com intenção de atribuir explicações para os sucessos e fracassos obtidos no desempenho de tarefas. Ao invés desse entendimento, as autoras passam a considerar as crenças como ações performadas através da língua em momento de fala ou de escrita, com base em mudança de paradigma que passa justamente de positivista para construcionista, e que se reconhece como pesquisas discursivas que se alinham com uma visão mais relativista de mundo. Tal mudança repercute automaticamente em mudanças metodológicas diretamente relacionadas aos instrumentos e procedimentos de análise da pesquisa. Sobre essas mudanças, Kalaja (2018) alerta que o resultado de uma análise de dados pode ser a interpretação do pesquisador, e que essa intepretação precisa ser a mais detalhada possível para convencer o leitor a partir de grande número de especificações e também de exemplos que venham ilustrar a análise.

A próxima seção trata do outro conceito chave para esta pesquisa, as metáforas.

\section{SOBRE METÁFORAS}


REVISTA X, Curitiba, volume 14, n.3,227-250, 2019.

$\mathrm{Na}$ tentativa de obter dados mais contextuais acerca de crenças sobre o ensino e a aprendizagem de LE, as pesquisas nessa área passaram a considerar textos orais e/ou escritos dos participantes e também suas metáforas como possibilidades de ferramentas para geração de dados. Com base em Low e Cameron (1999) e Cameron e Maslen (2010), Wan et al. (2011, p. 404) destacam que o uso de metáforas na metodologia de pesquisa está baseado na ideia de que "identificar e discutir metáforas pode trazer pressupostos implícitos à consciência, ou encorajar reflexão pessoal, e como resultado oferecer alguma luz para as perspectivas individuais em dados tópicos." encontra-se a possibilidade de conhecer percepções, entendimentos, sentimentos e crenças das pessoas, ainda que não tenham sido completamente verbalizados. Isso faz da metáfora um recurso valioso para esse trabalho.

Outro aspecto importante sobre metáfora é o fato de ser entendida como um fenômeno cognitivo e social, e de poder agir como uma ferramenta de mediação nos espaços onde as interpretações são construídas. Esse recurso tem sido usado no processo de reflexão de alunos e professores e também para tomada de consciência de ambos, com o intuito de moldar as práticas de sala de aula e de mediar o entendimento das crenças; ainda, de antecipar comportamentos possíveis de se ver nos professores e nos alunos.

Conforme Wan et al. (2011), a maior parte desses estudos se apoia na teoria da metáfora conceitual de Lakoff e Johnson (2008) - que será usada neste trabalho; e nas noções da natureza interativa da língua e do pensamento, de Vygotsky (1980) dentro da teoria sociocultural.

Lakoff e Johnson (2008) estabelecem uma relação de apoio entre o sistema conceitual do ser humano e a metáfora. Para eles, nosso sistema conceitual tem natureza metafórica, ou seja, as metáforas dão sustentação para a maneira como vivemos:

Principalmente com base na evidência linguística, temos percebido que a maior parte do nosso sistema conceitual comum é metafórico por natureza. $\mathrm{E}$ encontramos uma forma de começar a identificar em detalhes exatamente como são as metáforas que estruturam como nós percebemos, como pensamos e o que fazemos. ${ }^{6}$ (LAKOFF e JOHNSON, 2008, p. 4), (tradução

\footnotetext{
5 identifying and discussing metaphors can bring implicit assumptions into awareness, or encourage personal reflection, and as a result provide some insights into individuals' perspectives on given topics. ${ }^{6}$ Primarily on the basis of linguistic evidence we have found that most of our ordinary conceptual system is metaphorical in nature. And we have found a way to begin to identify in detail just what the metaphors
} 
REVISTA X, Curitiba, volume 14, n.3,227-250, 2019.

minha)

Para exemplificar como um conceito é metafórico e como isso estrutura nossas atividades de rotina, eles tratam do conceito "argumento" e da metáfora conceitual “argumento é guerra", e mostram com frases do dia a dia como essa metáfora é representada através de algumas expressões como: suas reclamações são indefensáveis, suas críticas foram direto no alvo, ele derrubou todos os meus argumentos, (LAKOFF e JOHNSON, 2008, p.4, ênfase no original) ${ }^{7}$. A partir dessas expressões os autores propõem que "Muitas das coisas que fazemos ao argumentar estão parcialmente estruturadas pelo conceito de guerra ${ }^{8}$." (LAKOFF e JOHNSON, 2008, p.4, ênfase no original) Em oposição, se para uma determinada cultura o conceito de "argumento" tivesse relação com a metáfora conceitual "argumento é dança", nesse caso as expressões usadas para se referir a situações de argumento seriam diferentes, e os participantes de uma argumentação seriam dançarinos e o objetivo seria fazer uma apresentação esteticamente agradável.

Da mesma maneira Lakoff e Johnson (2008) apresentam a metáfora conceitual "tempo é dinheiro", com expressões que denotam como tempo é um recurso limitado e uma mercadoria de valor, e afirmam que isso se apresenta de várias maneiras na vida real. Entre elas temos pagamentos por hora, orçamentos anuais, e juros sobre empréstimos, por exemplo. Estes são exemplos do que os autores também chamam de metáforas estruturais, quando um conceito é metaforicamente estruturado de acordo com outro conceito.

Com isso em mente, podemos dizer que aquilo que a pessoa expressa metaforicamente está diretamente ligado ao seu sistema de conceitos, e por isso carregado de significado. O que é o mesmo que dizer que da metáfora conceitual temse entendimento sobre conceitos internalizados pelo falante, e o uso delas na fala permite entender o significado daquilo que alguém diz, o que essa pessoa pensa, e também como essa pessoa age em situações reais.

Não é difícil perceber o uso de metáfora na fala de alunos, em diferentes pesquisas, ainda que esse não seja o procedimento metodológico adotado para aquele trabalho. Ao investigar crenças e emoções na aprendizagem de língua, Aragão (2011, p.

are that structure how we perceive, how we think, and what we do.

${ }^{7}$ Your claims are indefensible. His criticisms were right on target. He shot down all of my arguments.

${ }^{8}$ Many of the things we do in arguing are partially structured by the concept of war. 
REVISTA X, Curitiba, volume 14, n.3,227-250, 2019.

306) apresenta trechos de entrevistas em que uma participante relata "vir de uma família simples que luta muito para chegar onde está hoje." $\mathrm{O}$ autor destaca que "ela descreveu sua família e sua aprendizagem de inglês como uma luta." ${ }^{, 10}$ E acrescenta que "a imagem que ela tinha de si mesma em sala era a de uma aluna pisando em ovos, sendo cautelosa naquilo que falava." 11

Kramsch (2018), que serve de base metodológica para esta pesquisa, trata da construção subjetiva das crenças. Em seu trabalho, a autora resume como a formação metafórica de crenças acontece em relação ao pensamento, com base na psicologia discursiva e na semântica cognitiva (KRAMSCH, 2018). Ao término desse resumo, ela enfatiza que de maneira geral, a articulação e atribuição de crenças permitem construir e colocar em prática a realidade social na qual a pessoa está inserida; e também possibilitam mostrar como os alunos de língua constroem a realidade encontrada em suas experiências de aprendizagem.

Para ilustração desse resumo, apresento o mapa conceitual a seguir, elaborado conforme orientações de Cicuto e Correia (2012).

Mapa conceitual sobre a formulação metafórica de crenças em relação ao pensamento, conforme Kramsch (2003, p. 113)

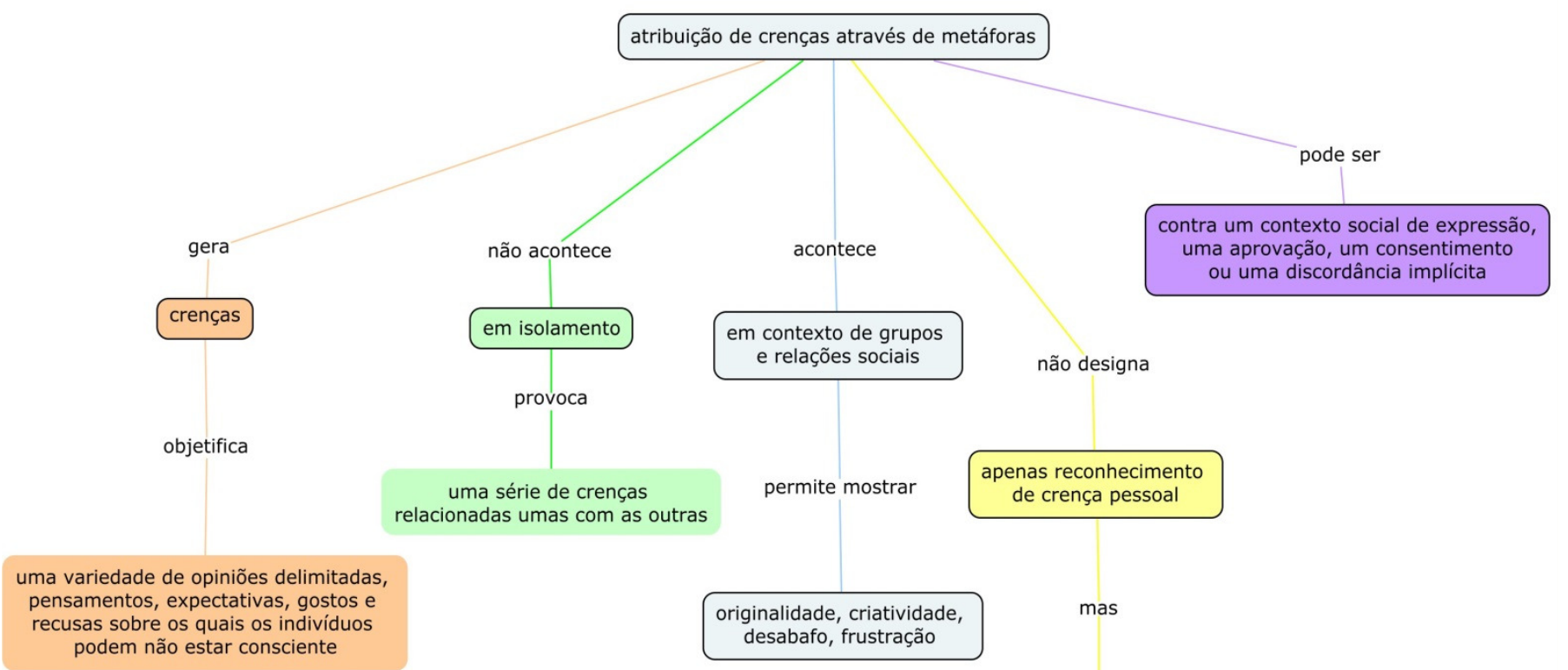

Fonte: elaboração minha (2019)

\footnotetext{
${ }^{9}$ I come from a simple family that has struggled hard to get where it is today.

${ }^{10}$ She described her family and her learning of English as a struggle.

${ }^{11}$ The image she had of herself in class was that of a student stepping on eggs, being cautious of what she would say.
} 
REVISTA X, Curitiba, volume 14, n.3,227-250, 2019.

Do mapa conceitual acima, destaco o fato de a atribuição de crenças através de metáforas ser capaz de gerar outras crenças. Isso é o mesmo que dizer que enquanto compartilhamos o que pensamos sobre um determinado assunto, ou seja, nossas crenças, simultaneamente geramos outras, pelo processo de verbalização ou escrita daquilo que pensamos ou entendemos sobre alguma coisa. Faço esse destaque para enfatizar a importância do trabalho de conscientização sobre o que pensamos; à medida que essa conscientização acontece, outras crenças são geradas. Esse fenômeno pode ser visto nas duas ramificações à esquerda do mapa conceitual.

Além desse entendimento sobre os desdobramentos que podem surgir da atividade de atribuição de crenças através de metáforas, Kramsch (2018) também expõe que o uso de metáfora como um recurso para analisar crenças pode ser feito a partir de duas abordagens diferentes, e refere-se a Gibbs $(1998,1999)$ para apresentar essas abordagens. A primeira é aquela em que o pesquisador processa uma metáfora explícita que normalmente é obtida ao completar uma frase dada. A segunda é aquela em que o pesquisador aplica processamento metafórico em um texto autobiográfico produzido pelo participante. Neste trabalho, utilizarei a primeira abordagem para a análise dos dados desta pesquisa.

$\mathrm{Na}$ abordagem que processa uma metáfora explícita, Gibbs (1999) explica que ao completar uma frase dada, o aluno mapeia o que ele chama de domínio fonte e domínio alvo. Na metáfora "aprender uma língua é como viajar para novos lugares"12, o domínio fonte é "viajar" e o domínio alvo "aprender uma língua". Nessa tarefa de processar uma metáfora, pode-se ter um deslize entre fonte e alvo, ou seja, é possível que nem todos os aspectos de viagem possam ser interpretados sob o prisma da aprendizagem de língua. Ainda, diferentes falantes têm diferentes repertórios sobre o que vem a ser viajar. Pode ser pra perto ou pra longe, pode ser com ou sem paradas, pode ou não ter destino certo, pode ser agradável ou estressante. De igual modo, aprender uma língua pode ser uma tarefa realizada com ou sem ajuda, pode ser fácil ou difícil, pode ser competitiva ou não. Por causa das diferentes possibilidades que se pode aplicar sobre o domínio fonte e o domínio alvo é que Kramsch (2018) menciona Hanks (2000, p. 22,29). Ele diz:

formular uma crença inarticulada é deste modo transformá-la... para simultaneamente o que é dito... há vários tipos de pré-suposições, vinculações, implicaturas e inferências contextuais, qualquer uma delas pode

${ }^{12}$ Language learning is like travelling to new places 
REVISTA X, Curitiba, volume 14, n.3,227-250, 2019.

ser reivindicada para ser formulada usada na fala. ${ }^{13}$ (HANKS, 2000, p. 22, 29)

Isso é o mesmo que dizer que, ainda que várias pessoas entendam que aprender uma LE é como viajar para lugares novos, não significa que suas opiniões sobre o processo de aprendizagem sejam iguais. E mais, as diferenças podem existir não apenas entre pessoas distintas, mas também para o mesmo indivíduo em momentos diferentes da vida. Esse entendimento se alinha com o de Barcelos (2006, 2018) mencionado anteriormente, sobre as crenças serem, dinâmicas e emergentes; socialmente construídas e contextualmente situadas; mediadas; experienciais; paradoxais e contraditórias.

Seguindo a abordagem que processa metáforas explicitas, este trabalho se propõe a destrinchar metáforas produzidas por alunos, sobre a aprendizagem da pronúncia de LE. Assim, a próxima seção tratará de contextualizar os procedimentos desta pesquisa e seus participantes.

\section{SOBRE ESTA PESQUISA}

Este artigo é um trabalho piloto que serve de base para uma pesquisa de doutorado em andamento. Para o recorte apresentado aqui, os dados foram gerados com acadêmicos do primeiro período ${ }^{14}$ do Curso de Letras Inglês da Universidade Tecnológica Federal do Paraná (UTFPR), obtidos em setembro e outubro de 2017. Dos 40 acadêmicos abordados para responder ao questionário ${ }^{15}$ compartilhado via google drive, 10 se prontificaram a participar da pesquisa. Deste número, sete eram do gênero feminino e três do gênero masculino. Os participantes foram pedidos para completar a frase “Aprender a pronúncia de uma língua estrangeira é como ...”. Das respostas obtidas, oito sentenças foram analisadas. Duas respostas foram excluídas por não se aterem ao conceito de metáfora proposto, que estabelecia uma relação entre o conceito fonte "aprender pronúncia" e o conceito alvo. As respostas não analisadas são "entender o contexto sociocultural" e "aprender a escrever de acordo com a gramática padrão, difícil". No caso dessas respostas, o conceito alvo apresentado pelos participantes não propôs tal relação.

\footnotetext{
${ }^{13}$ To formulate an unarticulated belief is thereby to transform it... for alongside what is 'said' ... there are various sorts of presuppositions, entailment, implicature and contextual inference any of which might be claimed to be formulated in my utterance.

${ }^{14}$ Apesar de estar ciente que os calouros do curso de Letras Inglês da UTFPR podem ingressar com alguma proficiência em língua inglesa, não foi objetivo deste artigo investigar o nível de proficiência dos participantes e como ele poderia se relacionar com os resultados desta pesquisa.

${ }^{15} \mathrm{O}$ questionário foi composto por apenas três perguntas (nome, e-mail, gênero e frase para completar)
} 
REVISTA X, Curitiba, volume 14, n.3,227-250, 2019.

Assim, as oito sentenças analisadas neste trabalho são:

- Participante 1 - Aprender a tocar um instrumento musical. Reconhecer o timbre, perceber a afinação, aprender o ritmo e adquirir velocidade e destreza

- Participante 2 - Reaprender a andar

- Participante 3 - Domar um leão

- Participante 4 - Andar de bicicleta

- Participante 5 - Ser destro e começar a fazer tudo com a mão esquerda.

- Participante 6 - Aprender a falar novamente.

- Participante 7 - Aprender a falar de outro jeito.

- Participante 8 - Aprender a gaguejar novamente, assim como no português quando nós somos bebês.

Após seleção das sentenças a serem consideradas, o processo de análise aconteceu em três etapas: a) categorização das sentenças em grupos que pudessem indicar a mesma categoria de conceitos metafóricos, como atividade física, por exemplo (Tabela 1); b) categorização das sentenças em grupos paradoxais (Tabela 2); e, c) problematização das metáforas a partir de destrinchamento das partes domínio fonte e domínio alvo.

A primeira etapa resultou na categorização das sentenças em grupos conceituais metafóricos da seguinte maneira:

Tabela 1 - Grupos conceituais metafóricos e sentenças dos alunos

\begin{tabular}{|c|c|}
\hline $\begin{array}{c}\text { GRUPOS CONCEITUAIS } \\
\text { METAFÓRICOS }\end{array}$ & SENTENÇA DO ALUNO \\
\hline $\begin{array}{l}\text { 1. Aprender a habilidade da fala (3 } \\
\text { respostas) }\end{array}$ & $\begin{array}{l}\text { - Aprender a falar novamente (participante 6) } \\
\text { - Aprender a falar de outro jeito (participante 7) } \\
\text { - Aprender a gaguejar novamente, assim como no } \\
\text { português quando nós somos bebês (participante } \\
\text { 8) }\end{array}$ \\
\hline $\begin{array}{l}\text { 2. Exigir-se em coordenação } \\
\text { motora e equilíbrio ( } 3 \text { respostas) }\end{array}$ & $\begin{array}{l}\text { - Reaprender a andar (participante 2) } \\
\text { - Andar de bicicleta (participante 4) } \\
\text { - Ser destro e começar a fazer tudo com a mão } \\
\text { esquerda. (participante 5) }\end{array}$ \\
\hline $\begin{array}{l}\text { 3. Usar de coragem / Estar-Entrar } \\
\text { em contato com algo perigoso ( } 1 \\
\text { reposta) }\end{array}$ & • Domar um leão (participante 3) \\
\hline $\begin{array}{l}\text { 4. Empenhar-se em uma atividade } \\
\text { artística ( } 1 \text { resposta) }\end{array}$ & $\begin{array}{l}\text { - Aprender a tocar um instrumento musical. } \\
\text { - Reconhecer o timbre, perceber a afinação, }\end{array}$ \\
\hline
\end{tabular}


REVISTA X, Curitiba, volume 14, n.3,227-250, 2019.

aprender o ritmo e adquirir velocidade e destreza. (participante 1)

A segunda etapa gerou a Tabela 2. Essa tabela mostra paradoxos estabelecidos a partir das sentenças dos alunos. Esse critério foi escolhido também aos moldes da pesquisa de Kramsch (2018), mas principalmente por alusão a uma das características das crenças apresentada por Barcelos (2018) - as crenças são paradoxais. Também foi escolhido como forma de trabalhar com os resultados por tratar da complexidade e característica paradoxal das metáforas que representam crenças dos alunos. Tal complexidade vem corroborar a ideia de que não seria possível aplicar análise positivista aos dados, por tentar estabelecer relação clara de causa e efeito entre crenças e comportamentos. Para uma pesquisa interpretativista como esta, que entende as crenças como sendo paradoxais, é importante que haja margem para possibilidades ao invés de certezas, para variedades ao invés de categorizações, para imprecisões ao invés de determinações.

$\mathrm{Na}$ Tabela 2, representamos a construção de um espaço mental que se caracteriza por ser ambíguo, contraditório, que se modifica e, acrescento ainda, que se exige, em virtude do caráter paradoxal que estabelece.

Tabela 2 - Paradoxos e sentenças dos alunos

\begin{tabular}{|c|c|}
\hline PARADOXO & SENTENÇA DO ALUNO \\
\hline $\begin{array}{l}\text { a. Aprender algo que já sabe (4 } \\
\text { respostas) }\end{array}$ & $\begin{array}{l}\text { - Aprender a falar novamente (participante 6) } \\
\text { - Aprender a falar de outro jeito (participante 7) } \\
\text { - Aprender a gaguejar novamente, assim como } \\
\text { no português quando nós somos bebês } \\
\text { (participante 8) } \\
\text { - Reaprender a andar (participante 2) }\end{array}$ \\
\hline $\begin{array}{l}\text { b. Desenvolver uma atividade que } \\
\text { já sabe que terá dificuldade (1 } \\
\text { reposta) }\end{array}$ & $\begin{array}{l}\text { - Ser destro e começar a fazer tudo com a mão } \\
\text { esquerda (participante 5) }\end{array}$ \\
\hline $\begin{array}{l}\text { c. Domar algo mais forte que você } \\
\text { (1 resposta) }\end{array}$ & - Domar um leão (participante 3) \\
\hline $\begin{array}{l}\text { d. Aprender com domínio amplo (1 } \\
\text { resposta) }\end{array}$ & $\begin{array}{l}\text { - Aprender a tocar um instrumento musical. } \\
\text { Reconhecer o timbre, perceber a afinação, } \\
\text { aprender o ritmo e adquirir velocidade e } \\
\text { destreza (participante 1) }\end{array}$ \\
\hline
\end{tabular}

$\mathrm{O}$ aspecto paradoxal destacado nas sentenças dos alunos, na Tabela 2, representa principalmente a complexidade das crenças. Aqui, proponho que esse aspecto seja 
REVISTA X, Curitiba, volume 14, n.3,227-250, 2019.

entendido a partir de dois pontos de vista distintos: cognitivo e emocional, e que tanto cognitiva quanto emocionalmente há, da parte do aluno, um conflito que também se apresenta de forma paradoxal. Nesse conflito, a aprendizagem pode ser igualmente desafiadora e desanimadora. Afinal, ele alterna seus esforços para ora aprender algo que já sabe (paradoxo "a") ou algo que não se imagina ser possível aprender (paradoxos "b", "c" e "d"). É como se racionalmente sua mente emitisse mensagem para realizar a atividade da aprendizagem, porém, racionalmente também enviasse mensagem dizendo que já se aprendeu, provocando um movimento de avanço e recuo. Da mesma forma, é como se emocionalmente seus impulsos o direcionassem para a aprendizagem, e ao mesmo tempo o fizessem recuar com sentimentos de impossibilidade de realização da tarefa. Novamente, com movimentos de avanço na direção da aprendizagem da pronúncia, mas também de recuo.

Por fim, a terceira etapa desta análise trata da problematização das sentenças trazidas pelos alunos a partir do destrinchamento das partes domínio fonte e domínio alvo. É importante destacar que, da mesma forma que na primeira e na segunda etapa, quando da categorização das sentenças em grupos conceituais metafóricos e dos paradoxos, o destrinchamento aqui também é suscetível ao sistema conceitual da pesquisadora, uma vez que esses participantes não foram entrevistados para expansão dos dados.

De acordo com Lakoff (1993) e Steen (1999), podemos analisar uma metáfora sob três pontos de vista diferentes: construto conceitual, que dá espaço para os aspectos paradoxais das crenças; construto gramatical, que se esforça para expressar o inexprimível; e construto discursivo, que permite moldar as ideias de uma forma subjetiva, inclusive com uso de expressões e conceitos que tratam da rotina diária.

Este trabalho vai fazer a problematização e destrinchamento das sentenças dos alunos sob o prisma do construto conceitual. É, então, pensando em conceitos que levanto os questionamentos abaixo, sobre as sentenças dos alunos, para destrinchar e problematizar cada uma delas.

Antes disso, considero importante ressaltar que de forma alguma pretendo estabelecer que os questionamentos que apresento neste destrinchamento são os únicos possíveis para as expressões e conceitos, para as categorias de metáfora ou para o aspecto paradoxal apresentado anteriormente. Aliás, considerar que eles não estão acabados é parte integrante da abordagem metodológica interpretativista que utilizo 
REVISTA X, Curitiba, volume 14, n.3,227-250, 2019.

nesta pesquisa. Então, destaco que outras interpretações são possíveis; que elas provavelmente variam de acordo com a trajetória daquele que se propõe a lidar com essas metáforas; e que aspectos culturais, emocionais e espirituais podem ter grande presença nessa tarefa de consideração discursiva. Proponho com isso, que a discursividade nessa pesquisa seja considerada tanto para aquele que produziu as metáforas, quanto para aquele que interagiu ou venha interagir com ela.

\section{Do grupo conceitual metafórico: Aprender habilidade da fala}

Sentença: Aprender a falar novamente

Domínio fonte: falar

Domínio alvo: aprender a pronúncia de uma LE

Considerando que para o participante 6 aprender a pronúncia de uma LE é como aprender a falar novamente, penso no sentimento que rege a tarefa de ter que aprender novamente. Que sentimento é esse? Existe frustração por ter que aprender algo de novo? Existe novidade nessa reaprendizagem? Também, o que acontece com o que já se sabe falar? O conhecimento que já se tem sobre uma fala é usado nesse aprender a falar de novo? E ainda, por que aprender de novo?

A partir dessa sentença, proponho que a aprendizagem da pronúncia seja para esse aluno, uma tarefa que demanda um descolamento daquilo que ele já sabe sobre falar. E, exige que ele se submeta ao processo de aprendizagem da pronúncia conforme o verbo submeter realmente sugere, ou seja, acatando a novas normas, se sujeitando ao que está sendo posto, rendendo-se àquele processo.

\section{Sentença: Aprender a falar de outro jeito}

Domínio fonte: falar

Domínio alvo: aprender a pronúncia de uma LE

Para essa sentença do participante 7, existe um entendimento de que a fala pode ser de vários jeitos diferentes. Nesse caso, que outro jeito é esse? É como o falante nativo? Como é o sotaque? Na minha sala de aula existem pessoas que falam desse outro jeito? Quais as diferenças entre o jeito que já falo e esse outro jeito? Desse outro jeito ainda há espaço para outros jeitos? Com quem eu falo desse outro jeito? É fácil ou 
REVISTA X, Curitiba, volume 14, n.3,227-250, 2019.

difícil?

De forma parecida com o processamento metafórico da sentença anterior, podemos ter aqui o entendimento de que para esse aluno, aprender a pronúncia de uma LE pode envolver um movimento de abandono ou de distanciamento daquilo que já se sabe falar. Por outro lado, chamo a atenção para a possibilidade de entender que o "falar de outro jeito" proposto pelo aluno pode se transformar em muitos outros jeitos, tantos quantos forem as pessoas que falam essa LE. Com isso, poderia se ampliar o horizonte das pronúncias possíveis a partir dessa sentença.

Sentença: Aprender a gaguejar novamente, assim como no português quando nós somos bebês

Domínio fonte: gaguejar

Domínio alvo: aprender a pronúncia de uma LE

Nessa sentença do participante 8, a última do grupo de conceito metafórico falar, também proponho questionar sobre os sentimentos envolvidos nesse processo. Como se sente a pessoa que não é mais bebê, mas que gagueja como um? Existe frustração ou constrangimento quando se gagueja? O quanto se entende daquele que gagueja? Que recursos podem ser usados para ampliar a compreensão da fala de uma pessoa que gagueja?

Nesse caso, a aprendizagem da pronúncia se estabelece como um processo a ser lapidado, que inicialmente pode não resultar em uma produção oral de fácil entendimento. E que, conforme a prática e o tempo atuam em conjunto, a produção pode deixar a condição de "gaguejar" e alcançar o "falar".

\section{Do grupo conceitual metafórico: Exigir-se em coordenação motora e equilíbrio}

Sentença: Reaprender a andar

Domínio fonte: andar

Domínio alvo: aprender a pronúncia de uma LE

Sobre essa sentença do participante 2, podemos fazer perguntas como: Por que uma pessoa precisa reaprender a andar? Que contexto é esse? A pessoa esqueceu como se anda? Ela sofreu um acidente? O que gera essa necessidade de reaprender a andar? Quais recursos estão disponíveis? Há ajuda para isso? De quem? Como a pessoa já tinha 
REVISTA X, Curitiba, volume 14, n.3,227-250, 2019.

aprendido antes, pode reaprender sozinho? O que acontece se a pessoa cair?

Nesse contexto, proponho uma relação onde andar equivale à pronúncia, e aprender pode demandar inclusive esforço e cansaço físico. Para esse aluno, aprender a pronúncia também exige equilíbrio, como quando ainda não se tem segurança e/ou força para sustentar o corpo. Parece tratar de um processo complexo, onde mente e corpo precisam se alinhar de uma forma que os comandos da mente sejam bem realizados pelo corpo, e porque essa sentença é parte do grupo conceitual metafórico que se relaciona à coordenação motora, a pronúncia pode ser aprimorada como acontece com a criança que apresenta traços de coordenação motora grossa e depois, de coordenação motora fina.

Sentença: andar de bicicleta

Domínio fonte: andar de bicicleta

Domínio alvo: aprender a pronúncia de uma LE

No contexto da sentença do participante 4, podemos questionar: Com que idade se pode andar de bicicleta? Qual o sentimento ao sentir a brisa tocando o rosto quando se anda de bicicleta? A pessoa consegue se equilibrar na bicicleta? A bicicleta tem rodinhas? Alguém está segurando a bicicleta? Quem? A superfície onde se está aprendendo é plana ou esburacada? Tem carros passando do lado? A bicicleta é do tamanho apropriado para a pessoa que está aprendendo?

Sobre tombos e erros, proponho que aprender a pronúncia corresponde a equilibrar-se na bicicleta, e cair corresponde a cometer erros. Com isso, os tombos seguidos de novas tentativas de se equilibrar sobre a bicicleta equivalem aos erros de pronúncia cometidos, que de igual modo podem ser seguidos de outras tentativas.

Sobre sentir-se seguro no ambiente de aprendizagem, proponho que as rodinhas sejam entendidas como a ajuda do professor e o apoio dos colegas; e a superfície plana ou esburacada o ambiente de sala de aula por onde os alunos transitam, que podem contribuir para uma trajetória mais tranquila ou podem trazer desconfortos para a aprendizagem da pronúncia.

Sentença: Ser destro e começar a fazer tudo com a mão esquerda.

Domínio fonte: ser destro e fazer tudo com a mão esquerda

Domínio alvo: aprender a pronúncia de uma LE 
REVISTA X, Curitiba, volume 14, n.3,227-250, 2019.

Essa sentença do participante 5 pode ser problematizada a partir de perguntas como: Qual o sentimento ao fazer algo que não se sente capaz? É preciso fazer tudo com a mesma precisão como se estivesse usando a mão direita? Existe espaço para adaptação e treino? Qual é a situação que exige essa mudança de mãos?

De novo, parece haver uma analogia entre aprender a pronúncia e um processo de refinamento. Naturalmente, ao começar a fazer as coisas com a mão esquerda, sendo destro, pode-se ter dificuldade de equilíbrio, de precisão e de tempo para execução de tarefas. Nesse sentido, aprender a pronúncia da LE pode envolver estágios em que a pronúncia não tenha muita precisão, e que exigirão do aluno tempo e treino para que seja melhorada ou refinada.

\section{Do grupo conceitual metafórico: Usar de coragem / Estar-Entrar em contato com} algo perigoso

Sentença: Domar um leão

Domínio fonte: domar um leão

Domínio alvo: aprender a pronúncia de uma LE

Esse grupo conceitual traz apenas a sentença do participante 3, e ela pode ser destrinchada com perguntas como: É possível domar um leão? Quem consegue? Como a pessoa se sente diante do leão? É preciso treino para se domar um leão? Que idade ele tem? É um leão bebê ou adulto? Existem equipamentos de segurança? Quais são os riscos dessa tarefa? O que ela pode fazer quando se sentir ameaçada? Existe um tempo para se desenvolver essa habilidade?

Nesse contexto, parece que a aprendizagem da pronúncia é algo extremamente difícil, pois o uso malsucedido das técnicas pode levar a riscos físicos, inclusive; o que exige do aluno, então, muita coragem. Nesse caso, a pronúncia equivale ao leão, um animal que na mesma medida em que pode ser admirável por sua imponência, segurança e beleza, também pode ser assustador. Em outras palavras, a pronúncia pode também representar imponência, segurança e beleza na fala, e ao mesmo tempo ser assustador para o aluno.

\section{Do grupo conceitual metafórico: Empenhar-se em uma atividade artística}


REVISTA X, Curitiba, volume 14, n.3,227-250, 2019.

Sentença: Aprender a tocar um instrumento musical. Reconhecer o timbre, perceber a afinação, aprender o ritmo e adquirir velocidade e destreza.

Domínio fonte: tocar um instrumento com destreza

Domínio alvo: aprender a pronúncia de uma LE

Essa sentença do participante 1 traz muitos itens para serem observados e destrinchados. Entre eles, aponto: Qual o sentimento da pessoa diante de tantos elementos envolvidos na atividade? Que instrumento é esse? Exige esforço físico para essa atividade? Quanto tempo leva pra chegar a esse nível de destreza? Qual a diferença entre timbre e afinação? Qual a diferença entre ritmo e velocidade? Como esses elementos podem individualmente influenciar ou comprometer o resultado final?

Nesse contexto de aprendizagem da pronúncia, a riqueza dos detalhes apresentada pelo aluno, e o nível técnico proposto para a atividade de tocar um instrumento musical, juntos, representam alto grau de complexidade. Nesses termos, aprender a pronúncia de uma LE não se apresenta como uma atividade fácil; ao contrário, se põe como um processo bastante exigente. A quantidade de elementos listados na sentença do aluno indica necessidade de atenção para muitos elementos da pronúncia também. Parece que nessa perspectiva, por conta do detalhamento, elementos como ritmo, acento, entonação e fala conectada devem ser explorados na aprendizagem da pronúncia desde o início desse processo. É como se desde o início da aprendizagem, tudo precisasse ser produzido harmoniosamente, com refinamento.

\section{CONSIDERAÇÕES FINAIS}

Nos últimos anos, os estudos de crenças em contexto de ensino e aprendizagem de LE se moveram de um lugar que investigava as crenças das pessoas e a relação delas com seus comportamentos, e têm se firmado em um lugar que investiga as pessoas, considerando suas crenças, suas emoções, sua atitude e sua identidade, (KRAMSCH, 2018, p.110). Pesquisas com essa perspectiva apresentam conceito de crenças como sendo ações performadas através da linguagem ${ }^{16}$ (KALAJA e BARCELOS, 2018, p. 232). Tais pesquisas se concretizam a partir de uma abordagem contextual e discursiva, apresentam resultados formatos diferentes daqueles que estabelecem uma relação de causa e efeito para crenças e comportamentos, e podem inclusive não trazer respostas,

16 ... beliefs as actions performed through language 
REVISTA X, Curitiba, volume 14, n.3,227-250, 2019.

mas questionamentos para a área e o interlocutor, como faz esta pesquisa.

Com isso em mente, o objetivo de destrinchamento proposto neste texto é uma tentativa de entender figurativamente as crenças dos alunos, e oferecer aos envolvidos no processo de ensino e aprendizagem da pronúncia da LE possibilidades de interpretação do ambiente de sala de aula.

Entendo que para cada questionamento levantado no item que trata da problematização e destrinchamento das crenças, outros podem ser feitos. Porém, ainda que diferentes perguntas surjam, as relações entre domínio fonte e domínio alvo sugeridas aqui promovem um exercício de processamento metafórico que pode favorecer e facilitar o entendimento da visão que o aluno tem sobre a aprendizagem da pronúncia, e ainda dar origem a outras crenças.

Não se trata apenas do reconhecimento das crenças dos alunos, mas sim da implicação pedagógica que esse reconhecimento pode ter, através do compartilhamento e da reflexão, por alunos e professores. Conforme mencionado no item sobre metáforas, e representado no mapa conceitual deste trabalho, a articulação e atribuição de crenças através de metáforas compõem um processo que não acontece em isolamento, mas sim, dá origem a outras crenças sobre si e também sobre o grupo, Kramsch (2018).

Então, enunciar as crenças metaforicamente, e dialogar a respeito delas passa a ser uma forma de construir conhecimento sobre si, sobre o processo de aprendizagem e sobre o ambiente onde se está inserido. É o que Kramsch (2018) chama de construção subjetiva das crenças. Ainda, outro aspecto importante para o ambiente de sala de aula é o valor que podemos atribuir à tomada de consciência promovida por esse contato com as crenças. A partir do conhecimento de si os participantes do processo de ensino e aprendizagem podem ter maior e melhor agência sobre suas escolhas locais, contextuais, individuais e também sociais, como também são as crenças, conforme Kalaja e Barcelos (2018).

No que diz respeito a encaminhamentos de pesquisa possíveis a partir deste trabalho, entendo que uma entrevista com estes participantes pode ser importante para dar origem a outros dados sobre as mesmas crenças, bem como sobre os próprios alunos. Conforme Barcelos (2015) aponta as emoções têm relação direta com nossas crenças e nossa identidade; assim, explorar as metáforas apresentadas aqui dando enfoque às emoções dos alunos pode ser uma expansão para este trabalho, capaz de trazer entendimentos que as limitações metodológicas desta pesquisa não puderam 
REVISTA X, Curitiba, volume 14, n.3,227-250, 2019.

abordar, visto que o único instrumento de pesquisa usado aqui foi o questionário que deu origem às metáforas dos alunos.

Por fim, como parte de pilotagem de minha pesquisa de doutorado, este trabalho tem sua importância fundamentalmente em minhas escolhas metodológicas, por conta das leituras trazidas aqui. Além disso, trata-se de um bom exercício de problematização e destrinchamento de metáforas a partir de questionamento possíveis para compreender o domínio fonte apresentado pelos alunos. A pesquisa de doutorado à que este trabalho serve ainda está em fase de definições sobre as duas abordagens discorridas por Kramsch (2018): o uso da metáfora explícita e o processamento metafórico de textos. E cogita, inclusive, a possibilidade de utilização dessas duas propostas.

\section{REFERÊNCIAS}

ALANEN, R. A sociocultural approach to young language learners' belief about language learning. In: Beliefs about SLA: New research approach. Middletown: Springer, p. 55-85, 2018.

ALMEIDA FILHO, J. C. P. Dimensões comunicativas no ensino de línguas. Campinas: Pontes, 1993.

ARAGÃO, R. Beliefs and emotions in foreign language learning. System, v. 39, n. 3, p. 302-313, 2011.

AVILA, A. P. A avaliação no ensino de espanhol: crença-ação de duas professoras da escola pública' 26/02/2018 undefined f. Doutorado em Letras, Universidade Federal de Santa Maria, Santa Maria, RS, 2018.

BARATA, M. C. C. M. Crenças sobre avaliação em língua inglesa: um estudo de caso a partir das metáforas no discurso de professores em formação - 01/12/2006 $230 \mathrm{f}$. Tese de Doutorado em Estudos Linguísticos, UFMG, Belo Horizonte, MG, 2006.

BARCELOS, A. M. F. A cultura de aprender língua estrangeira (inglês) de alunos de Letras. 1995. Dissertação de Mestrado em Linguística Aplicada, UNICAMP, Campinas, 1995.

- A cultura de aprender língua estrangeira (inglês) de alunos de letras. In: ALMEIDA FILHO, José Carlos Paes. (org.) O Professor de língua estrangeira em formação. Campinas: Pontes, 1999.

- Metodologia de pesquisa das crenças sobre aprendizagem de línguas: estado da arte. Revista Brasileira de Linguística Aplicada, v. 1, n. 1, p. 71-92, 2001.

As crenças de professores a respeito das crenças sobre aprendizagem de línguas de seus alunos. Ensinando e aprendendo inglês na universidade: formação de professores em tempos de mudança. Londrina: ABRAPUI, p. 55-65, 2003. 
REVISTA X, Curitiba, volume 14, n.3,227-250, 2019.

Cognição de professores e alunos: tendências recentes na pesquisa de crenças sobre ensino e aprendizagem de línguas. Crenças e ensino de línguas: foco no professor, no aluno e na formação de professores. Campinas: Pontes, p. 15-41, 2006.

Researching beliefs about SLA: A critical review. In: Beliefs about SLA. Middletown: Springer, p. 7-33, 2018.

BERNAT, E.; CARTER, N.; HALL, D. Beliefs about language learning: Exploring links to personality traits. University of Sydney Papers in TESOL, v. 4, n. 4, 2009.

CAMERON, L.; MASLEN, R. Metaphor analysis. Research practice in applied linguistics, social sciences and the humanities. Oakville, CT: Equinox, 2010.

CARVALHO, V. C. P. S. A aprendizagem de língua estrangeira sob a ótica de alunos de letras: crenças e mitos. 2000. Dissertação de Mestrado em Estudos Linguísticos Faculdade de Letras, UFMG, Belo Horizonte, 2000.

CICUTO, C. A. T.; CORREIA, P. R. M. Neighborhood analysis: a new approach to evaluate concept maps' propositional network. Revista Brasileira de Ensino de Física, v. 34, n. 1, p. 1-10, 2012.

COELHO, H.S.H. É possível aprender inglês em escola pública? Crenças de professores e alunos sobre o ensino de inglês em escolas públicas. Dissertação de Mestrado em Estudos Linguísticos, Faculdade de Letras, UFMG, Belo Horizonte, MG, 2005.

CRUZ, L. T. Entre o dizer e o fazer: implicações das crenças de professores em formação sobre o ensino de LI em escolas públicas - 31/08/2017 $180 \mathrm{f}$. Tese de Doutorado em Língua e Cultura, Universidade Federal da Bahia, Salvador Biblioteca Depositária: Biblioteca Central Reitor Macedo Costa, 2017.

DUFVA, H. Beliefs in dialogue: a Bakhtinian view. In: Beliefs about SLA. Middletown: Springer, p. 37-54, 2018.

GIBBS, R. W. The fight over metaphor in thought and language. Figurative language and thought, p. 88-118, 1998.

Researching metaphor. Researching and applying metaphor, p. 29-47, 1999.

GIMENEZ, T. Learners becoming teacher: an exploratory study of beliefs held by prospective and practising EFL teachers in Brazil. 1994. 340f. Tese de Doutorado, Lancaster: Lancaster University, 1994.

GOMES JUNIOR, Ronaldo Corrêa. Metáforas na rede: mapeamentos conceituais de estudantes universitários sobre aprendizagem de inglês - 01/02/2011 116 f. Dissertação de Mestrado em Estudos Linguísticos, Faculdade de Letras, UFMG, Belo Horizonte, MG, 2011.

HANKS, W. Belief ascription and the social production of belief. In: Colloquium on Belief Ascription, International Center for Semiotic and Cognitive Studies, Republic of San Marino, Italy, 2000. 
REVISTA X, Curitiba, volume 14, n.3,227-250, 2019.

HEIDER, F. Social perception and phenomenal causality. Psychological review, v. 51, n. 6 , p. $358,1944$.

The Psychology of Interpersonal Relations (Book Review). Social Forces, v. 37, n. 1, p. 272, 1958.

HOSENFELD, C. Students' Mini Theories of Second Language Learning. Association Bulletin, v. 29, n. 2, 1978.

Evidence of emergent beliefs of a second language learner: a diary study. In: In: Beliefs about SLA: New research approaches. Middletown: Springer, p. 37-54, 2018.

KALAJA, Paula. Student beliefs (or metacognitive knowledge) about SLA reconsidered. International Journal of Applied Linguistics, v. 5, n. 2, p. 191-204, 1995.

KALAJA, P.; BARCELOS, A. M. F. eds. Beliefs about SLA: New research approaches. Vol. 7. Middletown: Springer, 2018.

KALAJA, P., BARCELOS, A. M. F., e ARO, M. Revisiting Research on L2 Learner Beliefs: Looking Back and Looking Forward. In P. Garrett, \& J. M. Cots (Eds.), The Routledge Handbook of Language Awareness (pp. 222-237). New York: Routledge, 2016.

KRAMSCH, C. Metaphor and the subjective construction of beliefs. In: Beliefs about SLA: New research approaches. Middletown: Springer, p. 109-128, 2018.

LAKOFF, George. The contemporary theory of metaphor. In Andrew Ortony (ed.), Metaphor and Thought. Cambridge University Press. p. 202-251,1993.

LAKOFF, G.; JOHNSON, M. Metaphors we live by. University of Chicago Press, 2008.

LITTLEMORE, J.; LOW, G. Metaphoric competence, second language learning, and communicative language ability. Applied linguistics, v. 27, n. 2, p. 268-294, 2006.

LOW, G.; CAMERON, L. (Ed.). Researching and applying metaphor. Ernst Klett Sprachen, 1999.

MIRANDA, M. M. F. Crenças sobre o ensino-aprendizagem de língua estrangeira (inglês) no discurso de professores e alunos de escolas públicas. Dissertação de Mestrado em Linguística Aplicada. Universidade Estadual do Ceará, Fortaleza, 2005.

OLIVEIRA, B. M. Crenças, Motivações e Identidades de alunos de língua inglesa de uma escola particular' 31/03/2016 137 f. Mestrado em Letras, Universidade Federal de Viçosa, Biblioteca Central da Universidade Federal de Viçosa, 2016.

PAJARES, F. M. Teachers' Beliefs and Educational Research: Cleaning up a Messy Construction. Review of Educational Research. v. 62, n. 3, p. 307-332, 1992.

RILEY, P. The Guru and the Conjurer: Aspects of Counselling for Self-access. In BENSON, P. e VOLLER P. (Ed.). Autonomy and Independence in Language Learning. 
REVISTA X, Curitiba, volume 14, n.3,227-250, 2019.

New York: Longman, p. 114-131, 1997.

ROCHA, C.H. Provisões para Ensinar LE no Ensino Fundamental de $1^{\mathrm{a}}$ a $4^{\mathrm{a}}$ Séries: dos Parâmetros Oficiais e Objetivos dos Agentes. 269 Kleber Aparecido da Silva Linguagem \& Ensino, v.10, n.1, p.235-271, jan./jun.2007 Dissertação de Mestrado em Linguística Aplicada, Instituto de Estudos da Linguagem, UNICAMP, Campinas, 2006.

SAKUI, K.; GAIES, S. J. A case study: Beliefs and metaphors of a Japanese teacher of English. In: Beliefs about SLA: New research approaches. Middletown: Springer, p. 153-170, 2018.

SILVA, L.O. Crenças sobre aprendizagem de língua estrangeira de alunos formandos de Letras: um estudo comparativo. Dissertação de Mestrado, UFMG, Belo Horizonte, MG, 2001.

SILVA, K. A. Crenças e aglomerados de crenças de alunos ingressantes de Letras (inglês). 2005. Dissertação de Mestrado em Linguística Aplicada, UNICAMP, Campinas, 2005.

SILVA, M. M. dos S. E. Metáfora de Aprendizagem: Um Olhar sobre Narrativas Multimodais de Aprendizes de Língua Inglesa - 13/05/2013 115 f. Mestrado em Estudos Linguísticos, UFMG, Belo Horizonte, 2013.

STEEN, G. From linguistic to conceptual metaphor in five steps. Amsterdam studies in the theory and history of linguistic science, series 4, p. 57-78, 1999.

TEIXEIRA, P. L. de F. A identidade do professor de Inglês: discursos, narrativas e crenças sobre ensinar inglês no Tocantins' 28/11/2018 129 f. Mestrado em Letras, Ensino de Língua e Literatura, Universidade Federal do Tocantins, Araguaína, Biblioteca Depositária: Prof. Francisco Severino de Oliveira Filho, 2018.

VYGOTSKY, L. S. Mind in society: The development of higher psychological processes. Harvard University Press, 1980.

WAN, W.; LOW, G. D.; LI, M. From students' and teachers' perspectives: Metaphor analysis of beliefs about EFL teachers' roles. System, v. 39, n. 3, p. 403-415, 2011.

WENDEN, A. Helping language learners think about learning. ELT Journal, v. 40, n. 1, p. 3- 12, 1986.

WOODS, D. The social construction of beliefs in the language classroom. In: Beliefs about SLA: New research approaches. Middletown: Springer, p. 201-229, 2018. 